\title{
ANALISIS EKONOMI USAHA RUMAH TANGGA NELAYAN PELAGIS KECIL DI KELURAHAN AEK HABIL, SIBOLGA, SUMATERA UTARA
}

\author{
Subhechanis Saptanto, Manadiyanto dan Rizki Aprilian Wijaya \\ Balai Besar Penelitian Sosial Ekonomi Kelautan dan Perikanan \\ JI. KS. Tubun Petamburan VI Jakarta 10260 \\ Telp. (021) 53650162, Fax. (021)53650159 \\ Diterima 30 Maret 2011-Disetujui 14 Oktober 2011
}

\begin{abstract}
ABSTRAK
Kota Sibolga merupakan salah satu wilayah penghasil ikan pelagis kecil di Indonesia. Salah satu desa perikanan di wilayah Sibolga adalah Kelurahan Aek Habil. Tujuan dari penelitian ini adalah untuk mengkaji usaha penangkapan ikan pelagis kecil di Kelurahan Aek Habil. Data yang digunakan dalam penelitian ini adalah data primer yang diperoleh dari hasil wawancara dengan responden pada bulan April 2010. Data sekunder berasal dari dinas perikanan dan kelautan dan berbagai literatur yang mendukung penelitian. Metode pengumpulan data yang digunakan adalah metode survey sedangkan metode analisis yang digunakan adalah metode statistik deskriptif. Hasil penelitian menunjukkan bahwa RC ratio pada saat musim puncak adalah sebesar 2,23 dan pada saat musim paceklik adalah sebesar 1,01. Pendapatan kepala keluarga pemilik, nahkoda dan ABK yang berasal dari perikanan secara harian masing-masing sebesar Rp 113.278,- ; 57.011,-- dan 45.773,-. Dari sisi pola konsumsi rumah tangga pada umumnya konsumsi untuk pangan lebih tinggi dibandingkan dengan konsumsi non pangannya.
\end{abstract}

Kata Kunci: Pelagis kecil, Sibolga, pancing ulur, ekonomi rumah tangga

Abstract : Analysis of Small-Pellagic Fisher's Household in Aek Habil, Sibolga, North Sumatera. By : Subhechanis Saptanto, Manadiyanto and Rizki Aprilian Wijaya.

The Regency of Sibolga is one of the center production for small-pellagic fish in Indonesia. One of the fisheries rural region in Sibolga is in the Aek Habil Village. This study aimed to analyse small pellagic fish in Aek Habil Village. Study was conducted in April 2010. Primary and secondary data were collected by interviewing respondents and secondary data were collected from many sources, such as marine affairs and fisheries local services and other relevant literatures. A survey method was used in this study. Data were analized using descriptive statistics and cross-tabulated techniques. Results show that $R C$ -ratio in peak season was 2,23 and famine season was 1,01. Income of ship owner, crew leader and crew from fisheries business were IDR 113,278, IDR 57,011 and IDR 45,773, respectively. From consumption pattern, household food expenditure was greater than non-food expendeiture, indicating that their welfare status were a relatively poor.

Keyword : Small pellagic fish, Aek Habil, hand line, household economic 


\section{PENDAHULUAN}

Basis data panel yang kuat sangat dibutuhkan untuk mengetahui informasi kondisi rumah tangga perikanan dan kelautan yang ada di Indonesia. Data dan informasi yang dihasilkan riset panel mikro bermanfaat bagi perencanaan pembangunan pedesaan, termasuk pedesaan, perikanan dan kelautan, terutama terkait dengan perubahanperubahan yang terjadi di pedesaan guna penyempurnaan program terkait. Hal ini misalnya terlihat dengan adanya studi yang menghasilkan pola pendapatan rumah tangga, pola konsumsi, keragaan usahatani dan curahan tenaga kerja dan kesempatan kerja (Erwidodo et al., 1995).

Pengalaman pada riset Panel Pertanian Nasional (Patanas) yang dilakukan oleh Kementerian Pertanian menghasilkan berbagai alternatif kebijakan antara lain didasarkan atas profil pendapatan dan konsumsi pedesaan (Kasryno et al., 1986). Kemudian, juga berupa perkembangan struktur produksi, ketenagakerjaan dan pendapatan rumah tangga pedesaan (Pasandaran et al., 1989). Berbagai alternatif kebijakan juga dihasilkan dari data Patanas dapat dilihat pada prosiding yang berjudul Perspektif Pembangunan Pertanian dan Pedesaan dalam Era Otonomi Daerah (Rusastra et al., 2000).

Manfaat data panel yang ada pada Patanas tersebut coba diterapkan pada Panel Keluatan dan Perikanan Nasional (Panelkanas) dengan adanya Panelkanas diharapkan dapat dihasilkan data tentang dinamika sosial ekonomi pedesaan perikanan dan kelautan. Tujuan dari penelitian ini adalah untuk melihat ekonomi usaha rumah tangga penangkapan ikan pelagis kecil di Kelurahan Aek Habil, Kota Sibolga, Sumatera Utara baik dari sisi usaha, pendapatan, dan konsumsi rumah tangga nelayan.

\section{METODOLOGI}

\section{Lokasi dan Waktu Penelitian}

Sibolga merupakan salah satu wilayah yang menghasilan ikan pelagis kecil seperti kakap merah, gembolo (kembung jantan), balato kuning (sejenis ikan selar), balato aceh/ogak (sejenis ikan layang), timpik (tongkol) dan tenggiri. Pada tahun 2009 tercatat produksi perikanan di Kota Sibolga berjumlah sekitar 52.217,67 ton dan rata-rata perkembangan produksi perikanan dari tahun 2005-2009 sekitar 16,28\% per tahun. Jumlah nelayan di Sibolga mengalami peningkatan dibandingkan tahun sebelumnya yaitu dari 7.606 orang pada tahun 2008 menjadi 8.360 orang di tahun 2009. Armada perikanan di Kota Sibolga pada tahun 2009 terdapat 340 kapal motor, 152 motor tempel, dan 33 kapal tanpa motor. Alat tangkap yang ada di Sibolga tahun 2009 sebagai berikut : 150 pukat cincin, 20 pukat pantai, 20 jaring insang hanyut, 33 jaring insang tetap, trammel net 6 buah, 104 buah bagan apung, 54 buah bagan tancap, 37 buah serok, rawai tetap 1 buah, pancing 169 buah dan bubu sebanyak 340 buah.

Sibolga dijadikan sebagai salah satu wilayah penelitian Panelkanas khususnya untuk tipologi perikanan tangkap laut di Sumatera Utara. Desa yang menjadi lokasi penelitian adalah Kelurahan Aek Habil yang berada di Kota Sibolga, Provinsi Sumatera Utara. Kelurahan Aek Habil berada di sekitar koordinat $1^{\circ} 44^{\prime} \mathrm{LU}$ dan $98^{\circ} 47^{\prime}$ BT. Pada tahun 2009 jumlah nelayan utama di Aek Habil sekitar 931 orang dan 108 orang nelayan sambilan. Pada umumnya alat tangkap yang digunakan di Aek Habil adalah alat tangkap pancing yang menggunakan armada motor tempel (BPS, 2010).

Waktu pengambilan data dilakukan pada bulan April 2010. Ruang lingkup kegiatan riset terdiri atas berbagai aktivitas yang diharapkan dapat menyediakan data dan 
informasi yang dapat menjadi dasar dalam penetapan perbaikan alternatif kebijakan di sektor kelautan dan perikanan terutama perikanan tangkap, perikanan budidaya, dan produk kelautan serta berbagai permasalahan yang terkait dengan pembangunan desa-desa kelautan dan perikanan.

\section{Jenis dan Sumber Data}

Jenis data yang digunakan dalam kajian ini adalah data primer yang berasal dari survey lapang dengan menggunakan kuesioner terstruktur dan didukung oleh data sekunder yang berasal dari Dinas Perikanan dan Kelautan Kota Sibolga. Data primer yang dikumpulkan meliputi usaha penangkapan, pendapatan dan konsumsi rumah tangga perikanan.

\section{Metode Pengumpulan Data}

Pengumpulan data primer dilakukan dengan menggunakan metode wawancara terhadap nelayan yang menangkap ikan pelagis kecil di Aek Habil. Sampel dalam penelitian ini berjumlah 28 responden. Penentuan responden dilakukan melalui stratified random sampling berdasarkan skala usaha dan pola usaha yang dilaksanakan. Data yang dikumpulkan diperlukan untuk mengetahui responden yang telah berganti profesi, pensiun atau telah meninggal dunia sehingga responden tersebut digantikan dengan responden lainnya yang memiliki karakter yang hampir sama. Responden yang diambil adalah mereka yang pada umumnya melakukan usaha penangkapan di Aek Habil dengan menggunakan alat tangkap pancing ulur yang banyak terdapat di Aek Habil.

\section{Metode Analisis Data}

Data yang telah dikumpulkan dan ditabulasi selanjutnya dianalisis secara deskriptif untuk mendapatkan gambaran ekonomi usaha rumah tangga penangkapan ikan pelagis kecil di Kelurahan Aek Habil secara komprehensif. Statistik deskriptif digunakan untuk mencari jumlah sampel, nilai maksimum dan minimum, ratarata dan standar deviasinya. Hasil dari analisis kemudian diinterpretasikan untuk menjawab tujuan penelitian. Analisis dilakukan pada modul usaha, pendapatan, konsumsi dan kelembagaan. Untuk modul usaha dilakukan analisa usaha dengan menghitung besar biaya tetap, variabel, dan total penerimaan selama satu tahun sehingga diketahui struktur biaya, penerimaan, dan besarnya keuntungan. Penghitungan keuntungan usaha menggunakan rumus :

$$
ת=\mathrm{TR}-\mathrm{TC}
$$

Total Cost (TC) dihitung melalui rumus :

$$
\mathrm{TC}=\mathrm{FC}+\mathrm{VC}
$$

Dimana

$л$ = Keuntungan Usaha (Business Profits)

$\mathrm{TR}=$ Total Penerimaan (Total Revenue)

$\mathrm{TC}=$ Total Biaya (Total Cost)

$\mathrm{FC}=$ Biaya Tetap (Fixed Costs)

$\mathrm{VC}=$ Biaya Variabel (Variable Costs)

RC Ratio diperoleh melalui rumus :

$$
\text { RC Ratio }=\frac{T R}{T C}
$$

Analisis pendapatan rumah tangga perikanan bertujuan untuk mengetahui besarnya pendapatan yang berasal dari pendapatan utama dan sampingan baik itu yang berasal dari kepala keluarga maupun anggota rumah tangganya. Analisis konsumsi digunakan untuk mengetahui besarnya konsumsi rumah tangga perikanan. Konsumsi rumah tangga berasal dari konsumsi pangan dan non pangan. Analisis kelembagaan digunakan untuk mengetahui jenis kelembagaan yang sudah ada serta peran dan fungsinya dalam masyarakat. 


\section{HASIL DAN PEMBAHASAN}

\section{Deskripsi Lokasi dan Karakteristik Nelayan}

Lokasi penelitian adalah Kelurahan Aek Habil, Kecamatan Sibolga Selatan, Kota Sibolga, Sumatera Utara. Kelurahan Aek Habil dapat dikategorikan sebagai kelurahan yang secara ekologi perairan termasuk daerah pantai yang berbatasan langsung dengan laut. Pendapatan masyarakatnya didominasi oleh hasil laut sebagai nelayan. Aek Habil adalah salah satu kelurahan penghasil produksi ikan laut di Kota Sibolga. Dalam kegiatannya banyak melibatkan nelayan skala kecil. Kelurahan Aek Habil merupakan kelurahan nelayan perikanan tangkap laut. Sarana penangkapan nelayan Aek Habil masih tergolong sederhana sehingga kelurahan ini masih tergolong skala tradisional.

Penduduk Kelurahan Aek Habil bagian terbesar $(72,5 \%)$ tenaga kerjanya terserap di sektor perikanan yang menunjukkan lapangan pekerjaan yang tersedia di kelurahan sebenarnya relatif lebih ke arah homogen. Berdasarkan aksesibilitasnya, Kelurahan Aek Habil telah mempunyai jalan yang baik yang dapat dilalui kendaraan roda empat. Penangkapan ikan pada umumnya dilakukan di wilayah Pulau Musala, Pulau Gosong dan Pulau Banyak. Lokasi tersebut telah dikenal oleh masyarakat nelayan sehingga pada dasarnya menjadi milik bersama.

Sampel responden dalam kajian ini pada umumnya adalah nelayan tradisional yang memiliki armada penangkapan kurang dari 10 GT dengan menggunakan motor tempel. Alat tangkap yang digunakan adalah pancing ulur. Sampel responden yang berjumlah 28 responden tersebut terdiri dari 14 orang yang berprofesi sebagai pemilik perahu, 7 orang sebagai nahkoda dan sisanya sebagai Anak Buah Kapal (ABK). Rata-rata umur responden adalah 50 tahun. Karakteristik responden nelayan di Aek Habil dapat dilihat pada Gambar 1.

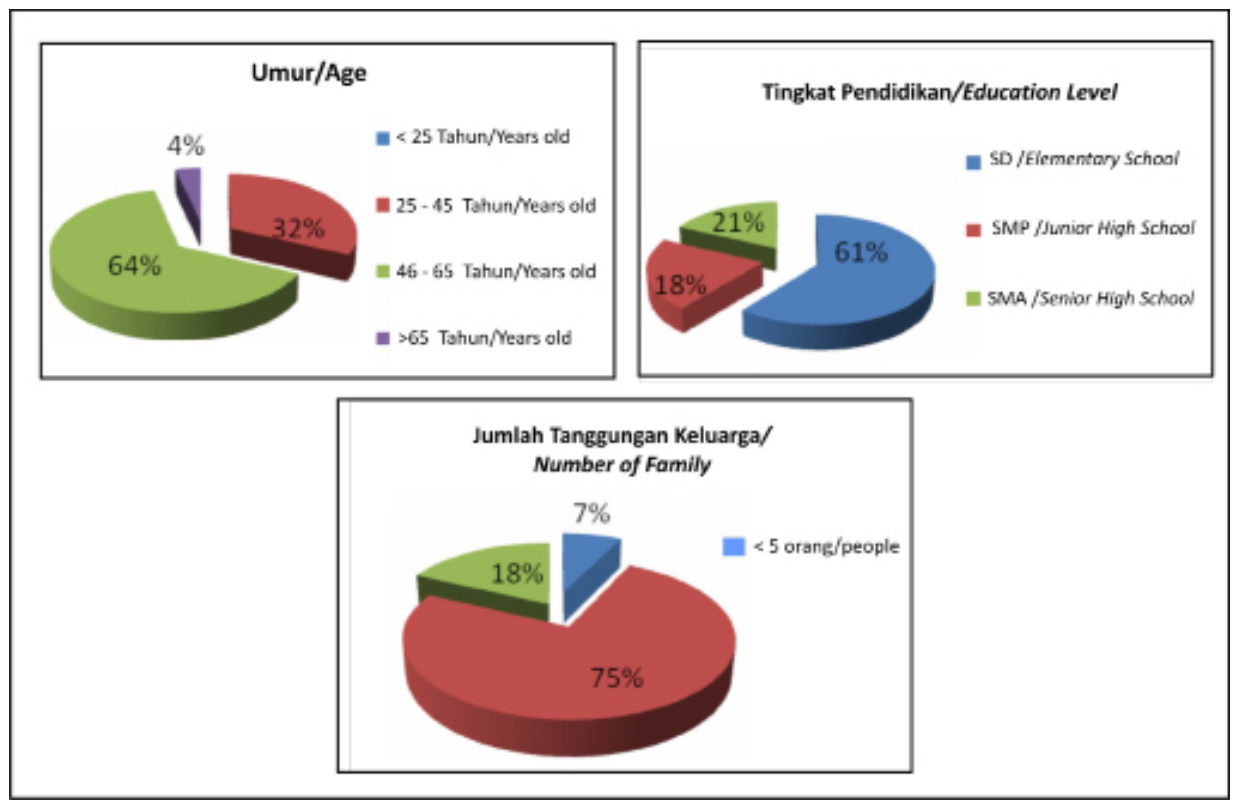

Sumber : Data primer (diolah), 2010/Source : Primary Data (Processed), 2010

Gambar 1. Karakteristik Responden Nelayan Aek Habil, Sibolga, Sumatera Utara, 2010. Figure 1. Characteristic of Fisher in Aek Habil, Sibolga, North Sumatera, 2010. 
Menurut Kamaludin (1994), umur digolongkan dalam tiga kategori golongan usia tidak produktif ( $<25$ dan $>65$ tahun), usia produktif (> 45 sampai 65 tahun) dan usia sangat produktif (25 sampai 45 tahun). Menurut hasil analisis, usia tidak produktif responden berjumlah $4 \%$, sangat produktif berjumlah $32 \%$, dan produktif berjumlah $64 \%$. Tingkat pendidikan responden pada umumnya hanya lulus sekolah dasar yang menunjukkan masih rendahnya tingkat pendidikan responden. Jumlah tanggungan keluarga pada umumnya berjumlah 5-8 orang (75\% responden) yang mengindikasikan bahwa pada umumnya keluarga nelayan di Aek Habil merupakan keluarga besar. Dilihat dari sisi etnis, pada umumnya berasal dari suku Batak, hanya sebagian kecil dari mereka yang berasal dari suku Jawa dan Padang. Rata-rata jumlah anggota rumah tangga responden adalah 7 orang.

\section{Usaha dan Musim Penangkapan}

Usaha penangkapan biasanya menggunakan alat tangkap pancing ulur. Alat tangkap pancing yang digunakan ada dua jenis yaitu pancing dengan umpan ikan dan bulu plastik. Jumlah hari/trip dalam menangkap ikan umumnya rata-rata berkisar 3-5 hari. Armada perikanan umumnya masih tergolong sederhana. Hal tersebut dapat dilihat dari panjang kapalnya $9 \mathrm{~m}$, lebarnya $1,7 \mathrm{~m}$ dan tinggi kapal 1,1 m. Kapal tersebut umumnya memuat 4 orang dan salah seorang berperan sebagai nahkoda.

Kapal yang digunakan oleh nelayan umumnya menggunakan dua buah mesin tempel berbahan bakar bensin campur dengan kekuatan mesin masing-masing sebesar 15 PK dan bermerk Yamaha. Musim penangkapan ikan di daerah Sibolga ada dua yaitu : musim puncak dan paceklik. Musim puncak biasanya pada bulan Januari hingga Juni sedangkan musim paceklik ada pada bulan Juli hingga Desember. Pada saat musim puncak terdapat sekitar 52 trip dan pada saat musim paceklik berjumlah 36 trip.

Investasi usaha penangkapan ikan pelagis kecil di Aek Habil rata-rata berjumlah Rp 19.985.231,-. Persentase investasi usaha yang besar digunakan untuk pembelian kapal dan mesin masing-masing sekitar $42,69 \%$ dan $32,24 \%$. Karena penangkapan umumnya dilakukan rata-rata 3-5 hari maka dibutuhkan peralatan masak. Selain itu dibutuhkan juga alat navigasi dan fish finder untuk menemukan lokasi ikan. Investasi usaha penangkapan ikan pelagis kecil di Kelurahan Aek Habil dapat dilihat pada Tabel 1.

Selain investasi, terdapat juga biaya tetap dan tidak tetap dalam usaha penangkapan ikan di Aek Habil. Unsur biaya tetap terdiri dari izin usaha, pajak lain, pemeliharaan perahu, pemeliharaan mesin, pemeliharaan alat tangkap dan biaya penyusutan. Rata-rata biaya tetap berjumlah $\mathrm{Rp}$ 12.296.551,- dimana persentase terbesar terdapat pada biaya penyusutan yaitu sebesar $37,01 \%$. Untuk biaya tetap usah penangkapan dapat dilihat pada Tabel 2.

Biaya tidak tetap dibagi menjadi tiga bagian yaitu : (a) Biaya operasional yang terdiri dari bensin, minyak campur, minyak tanah, oli/pelumas, garam, es balok dan umpan. Minyak campur yang digunakan adalah bensin yang berjumlah 29 liter dicampur dengan 1 liter oli. Umpan yang digunakan biasanya adalah udang baring/kacepe dan ikan kembung kecil; (b) Ransum yang terdiri dari beras, kopi, rokok, gula, mie instan, air tawar dan barang konsumsi lainnya; dan (c) Biaya lain-lain yang terdiri dari biaya bongkar muat, pembersihan kapal, jasa penyimpanan mesin dan sewa tambat.

Musim penangkapan sangat mempengaruhi biaya tidak tetap. Untuk biaya operasional baik itu musim puncak atau tidak, biaya paling besar dikeluarkan adalah untuk minyak campur sebagai bahan bakar kapal. Hanya sebagian kecil 
Tabel 1. Struktur Investasi Usaha Penangkapan Ikan Pelagis Kecil di Kelurahan Aek Habil, Sibolga, Sumatera Utara, 2010.

Table 1. Investment Structure of Small Pellagic Fishiery in Aek Habil, Sibolga, North Sumatera, 2010.

\begin{tabular}{|c|c|c|c|c|c|}
\hline No & Uraian/Description & $\begin{array}{l}\text { Umur Teknis } \\
\text { (Tahun)/ } \\
\text { Technical Age } \\
\text { (Years) }\end{array}$ & $\begin{array}{l}\text { Nilai (Rp)/ } \\
\text { Value (IDR) }\end{array}$ & $\begin{array}{l}\text { Standar } \\
\text { Deviasi/ } \\
\text { Standard } \\
\text { Deviation } \\
\end{array}$ & $\%$ \\
\hline A. & ASET & & 19.985 .231 & & 96,77 \\
\hline 1 & $\begin{array}{l}\text { Kapal }(\leq 10 \mathrm{GT}) / \text { Ship } \\
(\leq 10 \mathrm{GT})\end{array}$ & 5,85 & 8.530 .769 & 4.386 .416 & 42,69 \\
\hline 2 & $\begin{array}{l}\text { Mesin Yamaha } 15 \text { PK/ } \\
\text { Yamaha Machine } 15 \text { PK }\end{array}$ & 5,23 & 6.444 .231 & 4.527 .740 & 32,24 \\
\hline 3 & $\begin{array}{l}\text { Alat Tangkap Pancing } \\
\text { Ulur/Hand Line }\end{array}$ & 0,79 & 318.769 & 157.553 & 1,60 \\
\hline 4 & Lampu/Lampu & 0,69 & 14.154 & 14.707 & 0,07 \\
\hline 5 & $\begin{array}{l}\text { Alat Navigasi (Kompas, } \\
\text { GPS, dll.) - Garmen 128/ } \\
\text { Navigation Tool }\end{array}$ & 3,00 & 1.223 .077 & 1.482 .764 & 6,12 \\
\hline 6 & Tali Tambang/Rope & 0,46 & 723.462 & 1.689 .856 & 3,62 \\
\hline 7 & Fiber Ikan/Fish Fibre & 1,23 & 733.462 & 1.894 .095 & 3,67 \\
\hline 8 & $\begin{array}{l}\text { Komputer/Fish Finder - } \\
\text { Prono } 665\end{array}$ & 2,00 & 1.246 .154 & 2.598 .915 & 6,24 \\
\hline 9 & Aki/Accumulator & 0,46 & 424.615 & 733.174 & 2,12 \\
\hline 10 & Generator/Generator & 0,77 & 61.538 & 221.880 & 0,31 \\
\hline 11 & $\begin{array}{l}\text { Peralatan Masak/ } \\
\text { Cooking Tools }\end{array}$ & 0,77 & 200.000 & 302.765 & 1,00 \\
\hline 12 & $\begin{array}{l}\text { Keranjang Ikan/ } \\
\text { Fish Basket }\end{array}$ & 0,85 & 65.000 & 93.808 & 0,33 \\
\hline B & $\begin{array}{c}\text { Biaya Tidak Tetap untuk } \\
1 \text { trip/Variable Cost for } \\
1 \text { trip }\end{array}$ & & 667.353 & & 3,23 \\
\hline & Jumlah Total/Total & & 20.652 .583 & & 100 \\
\hline
\end{tabular}

Sumber : Data Primer (diolah), 2010/Source : Primary Data (Processed), 2010.

kapal yang menggunakan bahan bakar bensin. Untuk ransum, yang paling besar biayanya adalah untuk rokok dan beras.

Pada saat musim puncak persentase biaya untuk rokok dan beras masing-masing sebesar 44,75\% dan 33,93\% sedangkan untuk pada saat musim paceklik biaya untuk rokok dan beras masing-masing sebesar $38,77 \%$ dan 31,16\%. Untuk perbekalan (operasional dan ransum) biasanya disediakan oleh pemilik kapal dan namun ada juga yang berasal dari toke (pemodal).
Bila biaya perbekalan disediakan oleh toke maka hasil tangkapan harus dijual kepada toke dengan harga yang biasanya ditentukan oleh toke. Untuk biaya lainnya yang paling besar adalah biaya pembersihan kapal. Pembersihan kapal biasanya dilakukan oleh anak-anak yang masih remaja dan mereka biasa disebut dengan anak itik. Untuk biaya tambat tergantung kepada masing-masing tangkahan/pendaratan ikan. Di Aek Habil diketahui terdapat sekitar lima tangkahan 
Tabel 2. Struktur Biaya Tetap Usaha Penangkapan Ikan Pelagis Kecil per Tahun di Kelurahan Aek Habil, Sibolga, Sumatera Utara, 2010.

Table 2. Fixed Cost Structure of Small Pellagic Fishery per Year in Aek Habil, Sibolga, North Sumatera, 2010.

\begin{tabular}{|c|c|c|c|c|}
\hline No & Biaya Tetap/Fixed Cost & $\begin{array}{l}\text { Nilai (Rp)/ } \\
\text { Value (IDR) }\end{array}$ & $\begin{array}{c}\text { Standar Deviasi/ } \\
\text { Standard } \\
\text { Deviation }\end{array}$ & $\%$ \\
\hline 1 & IjinUsaha/Permit of business & 34.615 & 89.872 & 0,32 \\
\hline 2 & Pajak Lain/Other tax & 1.538 & 5.547 & 0,01 \\
\hline 3 & $\begin{array}{l}\text { Pemeliharaan Perahu/Nursing } \\
\text { Ship }\end{array}$ & 161.538 & 256.705 & 1,49 \\
\hline 4 & $\begin{array}{l}\text { Pemeliharan Mesin/Nursing } \\
\text { Machine }\end{array}$ & 265.385 & 488.784 & 2,45 \\
\hline 5 & $\begin{array}{l}\text { Pemeliharaan Alat Tangkap/ } \\
\text { Nursing Fishing Gear }\end{array}$ & 332.308 & 992.255 & 3,07 \\
\hline \multirow[t]{13}{*}{6} & $\begin{array}{l}\text { Biaya-Biaya Penyusutan/ } \\
\text { Depreciation }\end{array}$ & 7.646 .958 & & 70,54 \\
\hline & a. Kapal/Ship & 1.459 .211 & 3.927 .244 & 19,08 \\
\hline & b. Mesin/Machine & 1.231 .985 & 2.201 .167 & 16,11 \\
\hline & c. Alat Tangkap/Fishing Gear & 404.293 & 159.196 & 5,29 \\
\hline & d. Lampu/Lamp & 20.444 & 12.615 & 0,27 \\
\hline & $\begin{array}{l}\text { e. Alat Navigasi (Kompas, GPS, } \\
\text { dll.)/Navigation Tools }\end{array}$ & 407.692 & 204.422 & 5,33 \\
\hline & f. Tali Tambang/Rope & 1.567 .500 & 1.171 .440 & 20,50 \\
\hline & g. Fiber Ikan/Fish Fibre & 595.938 & 1.171 .571 & 7,79 \\
\hline & h. Komputer/Fish Finder & 623.077 & 584.587 & 8,15 \\
\hline & i. Aki/Accu & 920.000 & 872.628 & 12,03 \\
\hline & j. Generator/Generator & 80.000 & 80.000 & 1,05 \\
\hline & k. Peralatan Masak/Cooking Tools & 260.000 & 16.667 & 3,40 \\
\hline & I. Keranjang Ikan/Fish Basket & 76.818 & 104.272 & 1,00 \\
\hline \multirow[t]{2}{*}{7} & $\begin{array}{l}\text { Bunga Investasi ( } 12 \% / \text { tahun }) / \\
\text { Investment rate ( } 12 \% / \text { year) }\end{array}$ & 2.398 .228 & & 22,12 \\
\hline & Junlah/Total & 10.840 .570 & & 100 \\
\hline
\end{tabular}

Sumber : Data Primer (diolah), 2010/Source : Primary Data (Processed), 2010.

yaitu Tangkahan Aleng, Tangkahan Maslihah Sikumbang, Tangkahan Raja Silalahi, Tangkahan Nazara, dan Tangkahan Kelompok Nelayan Tolong Menolong (KNTM).

Struktur biaya tidak tetap usaha penangkapan ikan di Aek Habil dapat dilihat pada Tabel 3.
Dalam musim puncak, biaya total yang dikeluarkan adalah sebesar Rp 83.946.470,- sedangkan penerimaan sebesar Rp 116.777.043,- sehingga nilai $\mathrm{RC}$ ratio yang dihasilkan sebesar 2,23. Untuk musim puncak, biaya total yang dikeluarkan adalah sebesar Rp 33.507.593,dan penerimaannya sebesar Rp 44.645.751,- 
Tabel 3. Struktur Biaya Tidak Tetap Usaha Penangkapan Ikan Pelagis Kecil per Tahun di Kelurahan Aek Habil, Sibolga, Sumatera Utara, 2010.

Table 3. Variable Cost Structure of Small Pellagic Fishery per Year in Sub District Aek Habil, Sibolga, North Sumatera, 2010.

\begin{tabular}{|c|c|c|c|c|c|c|c|}
\hline \multirow[b]{2}{*}{ No } & \multirow[b]{2}{*}{ Uraian/Description } & \multicolumn{3}{|c|}{$\begin{array}{l}\text { Musim Puncak/ } \\
\text { Peak Season }\end{array}$} & \multicolumn{3}{|c|}{$\begin{array}{l}\text { Musim Paceklik/ } \\
\text { Famine Season }\end{array}$} \\
\hline & & $\begin{array}{l}\text { Nilai (Rp)/ } \\
\text { Value (IDR) }\end{array}$ & $\begin{array}{l}\text { Standar } \\
\text { Deviasi/ } \\
\text { Standard } \\
\text { Deviation }\end{array}$ & $\%$ & $\begin{array}{l}\text { Nilai (Rp)/ } \\
\text { Value (IDR) }\end{array}$ & $\begin{array}{l}\text { Standar } \\
\text { Deviasi/ } \\
\text { Standard } \\
\text { Deviation }\end{array}$ & $\%$ \\
\hline \multirow[t]{8}{*}{1} & $\begin{array}{l}\text { Operasional/ } \\
\text { Operational }\end{array}$ & 62.761 .979 & & 100 & 24.376.782 & & 100,00 \\
\hline & a. Bensin/Gasoline & 1.053 .107 & 2.153 .283 & 1,68 & 729.231 & 7.813 .311 & 2,99 \\
\hline & $\begin{array}{l}\text { b. Minyak Campur/ } \\
\text { Mixed oil }\end{array}$ & 37.201 .579 & 37.177 .255 & 59,27 & 14.041 .338 & 17.978.696 & 57,60 \\
\hline & $\begin{array}{l}\text { c. Minyak Tanah/ } \\
\text { Kerosene }\end{array}$ & 1.177 .473 & 452.416 & 1,88 & 598.811 & 413.797 & 2,46 \\
\hline & $\begin{array}{l}\text { d. Oli/Pelumas/ } \\
\text { Lubricant }\end{array}$ & 312.923 & 1.199 .538 & 0,50 & 218.769 & 838.615 & 0,90 \\
\hline & e. Garam/Salt & 1.430 .219 & 35.296 & 2,28 & 450.160 & 381.805 & 1,85 \\
\hline & f. Es Balok/Ice cube & 6.662 .654 & 1.637 .945 & 10,62 & 2.841 .195 & 1.799 .443 & 11,66 \\
\hline & g. Umpan/Bait & 14.924 .024 & 133.949 & 23,78 & 5.497 .278 & 5.721 .087 & 22,55 \\
\hline \multirow[t]{8}{*}{2} & $\begin{array}{l}\text { Ransum/ } \\
\text { Consumable }\end{array}$ & 16.831 .651 & & 100 & 7.321.757 & & 100,00 \\
\hline & a. Beras/Rice & 5.710 .846 & 1.606 .696 & 33,93 & 2.281 .651 & 1.641 .787 & 31,16 \\
\hline & b. Kopi/Coffee & 230.680 & 235.264 & 1,37 & 116.396 & 208.889 & 1,59 \\
\hline & c. Rokok/Cigarette & 7.532 .219 & 4.381 .288 & 44,75 & 2.838 .391 & 2.641 .537 & 38,77 \\
\hline & d. Gula/Sugar & 874.580 & 577.111 & 5,20 & 378.639 & 315.875 & 5,17 \\
\hline & $\begin{array}{l}\text { e. Mie Instan/ } \\
\text { Instant Noodle }\end{array}$ & 1.901 .609 & 516.195 & 11,30 & 1.329 .444 & 1.459 .802 & 18,16 \\
\hline & $\begin{array}{l}\text { f. Air Tawar/Fresh } \\
\text { Water }\end{array}$ & 118.349 & 57.993 & 0,70 & 82.740 & 57.375 & 1,13 \\
\hline & g. Lainnya/Others & 463.367 & 445.632 & 2,75 & 294.497 & 431.904 & 4,02 \\
\hline \multirow[t]{5}{*}{3} & Lain-lain/Others & 4.352 .840 & & 100 & 1.809 .053 & & 100 \\
\hline & $\begin{array}{l}\text { a. Bongkar Muat/ } \\
\text { Includeand exclude }\end{array}$ & 1.404 .142 & 1.546 .360 & 32,26 & 406.686 & 990.757 & 22,48 \\
\hline & $\begin{array}{l}\text { b. Bersih Kapal/ } \\
\text { Cleaning ship }\end{array}$ & 2.728 .047 & 1.419 .623 & 62,67 & 1.318 .225 & 1.188 .483 & 72,87 \\
\hline & $\begin{array}{l}\text { c. Sewa Tambat/ } \\
\text { Fishing port rental }\end{array}$ & 220.651 & 273.144 & 5,07 & 84.142 & 106.338 & 4,65 \\
\hline & $\begin{array}{l}\text { Total Biaya Variabel } \\
\text { per Musim/Total of } \\
\text { Variable Cost per } \\
\text { Season }\end{array}$ & \multicolumn{3}{|c|}{83.946 .470} & \multicolumn{3}{|c|}{33.507 .593} \\
\hline
\end{tabular}

Sumber : Data Primer (diolah), 2010/Source : Primary Data (Processed), 2010. 
sehingga nilai RC Rationya sebesar 1,01. Sistem bagi hasil dalam usaha penangkapan ikan pelagis kecil di Aek Habil dilakukan dengan cara penerimaan dikurangi terlebih dahulu dengan biaya perbekalan kemudian sisanya (pendapatan bersih) dibagi 7 bagian dimana pemilik kapal memperoleh 2,5 bagian, nahkoda mendapat 1,5 bagian dan masing-masing Anak Buah Kapal (ABK) mendapat 1 bagian (terdapat 3 orang $A B K)$. Analisis usaha penangkapan ikan pelagis kecil di Kelurahan Aek Habil dapat dilihat pada Tabel 4.

\section{Struktur Pendapatan Rumah Tangga}

Struktur pendapatan rumah tangga umumnya dibagi menjadi dua yaitu pendapatan yang berasal dari kepala keluarga dan anggota kepala keluarga. Sedangkan pendapatan dari masingmasing kepala keluarga dan anggota kepala keluarga dibagi menjadi pendapatan utama dan sampingan. Rata-rata pendapatan total pemilik kapal, nahkoda dan ABK masing- masing sebesar Rp 63.139.983, Rp 49.529.005,dan Rp 46.167.297,--. Untuk pendapatan utama kepala keluarga pemilik, nahkoda dan ABK yang berasal dari perikanan bila diasumsikan harian maka perharinya mereka mendapat masing- masing sebesar Rp 113.278,-; 57.011,-- dan 45.773,--

\section{Konsumsi Rumah Tangga}

Pengeluaran konsumsi merupakan salah satu indikator yang menentukan tingkat kesejahteraan rumah tangga. Khusus untuk konsumsi pangan, menurut Purwantini dan Ariani (2008), semakin tinggi pangsa pengeluaran konsumsi pangan berarti semakin kurang sejahtera rumah tangga tersebut. Sebaliknya, semakin rendah pengeluaran konsumsi pangan maka rumah tangga tersebut semakin sejahtera. Pengeluaran konsumsi rumah tangga yang dihitung dalam kurun waktu satu tahun baik untuk konsumsi pangan maupun non pangan. Konsumsi pangan berasal dari makanan pokok, protein nabati/hewani, sayur-sayuran, rokok, minyak goreng, buah-buahan, gula, kopi, teh, dan bumbu masak. Sedangkan konsumsi non pangan berasal dari biaya rekening listrik, Pajak Bumi dan Bangunan (PBB), Pajak kendaraan, pendidikan anak, pembelian sandang/pakaian dan pengeluaran lainnya.

Rumah tangga nelayan di Aek Habil menjadikan beras/nasi sebagai makanan pokoknya. Beras yang dikonsumi rata-rata sekitar $1 \mathrm{~kg} /$ hari. Lauk pauk utama yang banyak dikonsumsi adalah ikan laut karena pada umumnya ikan yang dikonsumsi adalah ikan yang berasal dari sebagian

Tabel 4. Analisis Usaha Penangkapan Ikan Pelagis Kecil di Kelurahan Aek Habil, Sibolga, Sumatera Utara, 2010.

Table 4. Rentability of Small Pellagic Fishery Captured in Aek Habil, Sibolga, North Sumatera, 2010.

\begin{tabular}{|c|c|c|c|}
\hline \multirow[b]{2}{*}{ No } & \multirow[b]{2}{*}{ Uraian/Description } & \multicolumn{2}{|c|}{ Nilai (Rp)/ Value (IDR) } \\
\hline & & $\begin{array}{c}\text { Musim Puncak/ } \\
\text { Peak Season }\end{array}$ & $\begin{array}{c}\text { Musim Paceklik/ } \\
\text { Famine Season }\end{array}$ \\
\hline \multirow[t]{3}{*}{1} & Total Biaya/Total Cost & 94.787 .040 & 44.348 .163 \\
\hline & a. Biaya Tetap/Fixed Cost(Rp) & 10.840 .570 & 10.840 .570 \\
\hline & b. Biaya Tidak Tetap/Variable Cost (Rp) : & 83.946 .470 & 33.507 .593 \\
\hline 2 & Penerimaan/Revenue (Rp) : & 211.564 .083 & 44.645 .751 \\
\hline 3 & Pendapatan bersih/Net Income(Rp) : & 116.777.043 & 297.588 \\
\hline 4 & RC Ratio & 2,23 & 1,01 \\
\hline
\end{tabular}

Sumber : Data Primer (diolah), 2010/Source : Primary Data (Processed), 2010. 
Tabel 5. Struktur Pendapatan Rumah Tangga per Tahun Berdasarkan Sumber Pendapatannya di Kel. Aek Habil, 2010.

Table 5. Structure of Fisher's Household Income per Year Based on According to Sources in Aek Habil, Sibolga, 2010.

\begin{tabular}{|c|c|c|c|c|c|c|c|c|c|}
\hline \multirow[b]{2}{*}{$\begin{array}{l}\text { Kategori/ } \\
\text { Categorize }\end{array}$} & \multicolumn{3}{|c|}{ Pemilik/Owner } & \multicolumn{3}{|c|}{ Nahkoda/Crew Leader } & \multicolumn{3}{|c|}{ ABK/Crew } \\
\hline & $\begin{array}{l}\text { Pendapatan } \\
\text { (Rp)/ } \\
\text { Income (IDR) }\end{array}$ & $\begin{array}{l}\text { Standar } \\
\text { Deviasi/ } \\
\text { Standard } \\
\text { Deviation }\end{array}$ & $\%$ & $\begin{array}{l}\text { Pendapatan } \\
\text { (Rp)/ } \\
\text { Income (IDR) }\end{array}$ & $\begin{array}{l}\text { Standar } \\
\text { Deviasi/ } \\
\text { Standard } \\
\text { Deviation }\end{array}$ & $\%$ & $\begin{array}{l}\text { Pendapatan } \\
\text { (Rp)/ } \\
\text { Income(IDR) }\end{array}$ & $\begin{array}{l}\text { Standar } \\
\text { Deviasi/ } \\
\text { Standard } \\
\text { Deviation }\end{array}$ & $\%$ \\
\hline $\begin{array}{l}\text { Kepala Keluarga/ } \\
\text { Householder }\end{array}$ & 46.966 .649 & & 74,38 & 26.039 .005 & & 52,57 & 16.917 .297 & & 36,64 \\
\hline a. Utama/Main & 41.346 .649 & 51.840 .202 & 88,03 & 20.809 .005 & 30.318 .898 & 79,91 & 16.707 .297 & 16.373 .800 & 98,76 \\
\hline b. Sampingan/Side & 5.620 .000 & 4.171 .043 & 11,97 & 5.230 .000 & 1.088 .944 & 20,09 & 210.000 & 127.279 & 1,24 \\
\hline $\begin{array}{l}\text { Anggota Keluarga/ } \\
\text { Household } \\
\text { member }\end{array}$ & 16.173 .333 & & 25,62 & 23.490 .000 & & 47,43 & 29.250 .000 & & 63,36 \\
\hline a. Utama/Main & 16.173 .333 & 11.985 .258 & 100 & 23.490 .000 & 16.418 .051 & 100 & 29.070 .000 & 40.347 .513 & 99,38 \\
\hline b. Sampingan/Side & - & - & 0 & 0 & & 0 & 180.000 & 84.853 & 0,62 \\
\hline Pendapatan & 63.139 .983 & & 100 & 49.529 .005 & & 100 & 46.167 .297 & & 100 \\
\hline $\begin{array}{l}\text { Rumah Tangga/ } \\
\text { Household Income }\end{array}$ & & & & & & & & & \\
\hline
\end{tabular}

Sumber : Data Primer (diolah), 2010/Source : Primary Data (Processed), 2010.

hasil tangkapan. Jenis konsumsi lainnya yang tergolong tinggi adalah rokok karena pada umumnya nelayan memiliki kebiasaan merokok. Dalam satu hari, mereka biasanya menghabiskan 1-2 bungkus rokok. Rata-rata pengeluaran konsumsi pangan nelayan di Aek Habil sebesar Rp 2.254.647/bulan. Untuk pengeluaran konsumsi non pangannya rata-rata sebesar Rp 1.243.622,-/bulan.

\section{KESIMPULAN DAN IMPLIKASI KEBIJAKAN}

\section{Kesimpulan}

Usaha penangkapan ikan pelagis kecil di Aek Habil yang menggunakan pancing ulur masih memiliki prospek yang cukup baik meskipun masih tergolong tradisional. Hal tersebut ditunjukkan oleh nilai $\mathrm{RC}$ ratio sebesar 2,23 pada musim puncak dan 1,01 pada saat musim paceklik. Ditinjau dari pendapatan, baik untuk pemilik kapal, nahkoda maupun
ABK dapat dikatakan masih tergolong cukup layak karena lebih besar dibandingkan dengan pengeluaran untuk konsumsinya (konsumsi pangan dan non pangan). Dari sisi kelembagaannya, peran kelompok nelayan di Aek Habil cukup memberikan pengaruh dalam memberikan solusi terhadap permasalahan-permasalahan yang ada pada nelayan.

\section{Implikasi Kebijakan}

Kendala yang dialami oleh nelayan adalah adanya ketidakpastian iklim yang mempengaruhi usaha penangkapan mereka. Mereka membutuhkan bantuan dari pemerintah baik fisik maupun non fisik. Bantuan fisik berupa bantuan BBM dan teknologi penangkapan (kapal, mesin dan alat tangkap). Permasalahan yang sering muncul adalah adanya pemberian bantuan dari pemerintah yang salah sasaran sehingga sering menimbulkan ketegangan antara kelompok nelayan 
dengan dinas setempat. Kajian Panelkanas ini juga menggali informasi mengenai responden yang berhak menerima bantuan dari pemerintah setempat. Selain itu bantuan non fisik dapat berupa sumbangsih pikiran dari peneliti yang melakukan riset Panelkanas di Aek Habil. Melalui bantuan ini diharapkan dapat menghasilkan basis data untuk menjawab permasalahan yang ada pada nelayan Aek Habil khususnya dan masyarakat perikanan tangkap laut pada umumnya.

\section{DAFTAR PUSTAKA}

BPS. 2010. Sibolga Dalam Angka 2010. Jakarta. 70 Hal.

DDepartemen Kelautan dan Perikanan. 2005. Revitalisasi Perikanan. Departemen Kelautan dan Perikanan. Jakarta

Erwidodo. 1995. Studi dinamika kesempatan kerja dan pendapatan di pedesaan, Metode Pemilihan Desa, Blok Sensus, dan Petani Responden. $86 \mathrm{Hal}$.

Kamaluddin, L.M. $1994 . \quad$ Strategi Penyiapan dan Kualitas SDM Pada Pembangunan Agribisnis Perikanan Indonesia.Makalah Seminar Sehari Himpunan Sosial Ekonomi Perikanan. IPB. Bogor. 20 Hal.

Kasryno, F., H. Nataatmadja, C. A. Rasahan. dan Y. Yisdja. 1986. Profil Pendapatan dan Konsumsi Pedesaan Jawa Timur. Pusat Penelitian Agro Ekonomi, Badan Litbang Pertanian. Departemen Pertanian. Jakarta. 141 Hal.
Kusnadi. 2006. Filosofi Pemberdayaan Masyarakat Pesisir. Humaniora. Bandung. $104 \mathrm{Hal}$.

Pasandaran, E., P. Simatupang, T. Sudaryanto, A. Suryana, C.A. Rasahan dan A. Djauhari. 1989. Prosiding Patanas Perkembangan Struktur Produksi, Ketenagakerjaan dan Pendapatan Rumah Tangga Pedesaan, Pusat Penelitian Agro Ekonomi. Badan Litbang Pertanian. Kementerian Pertanian. Jakarta.312 Hal.

Purwantini, T.B. dan M. Ariani. 2008. Pola Pengeluaran dan Konsumsi Pangan pada Rumah Tangga Petani Padi. Disampaikan pada Seminar Nasional Dinamika Pembangunan Pertanian dan Pedesaan: Tantangan dan Peluang Bagi Peningkatan Kesejahteraan Petani. Bogor, 19 Nopember 2008. Pusat Analisis Sosial Ekonomi dan Kebijakan Pertanian. Departemen Pertanian.16 Hal.

Rusastra, I.W., A.R. Nurmanaf., S.H. Susilowati dan E. Jamal., B. Sayaka. 2000. Perspektif Pembangunan Pertanian dan Pedesaan Dalam Era Otonomi Daerah. Pusat Penelitian Sosial Ekonomi Pertanian. Badan Litbang Pertanian. Kementerian Pertanian. Jakarta.397 Hal. 


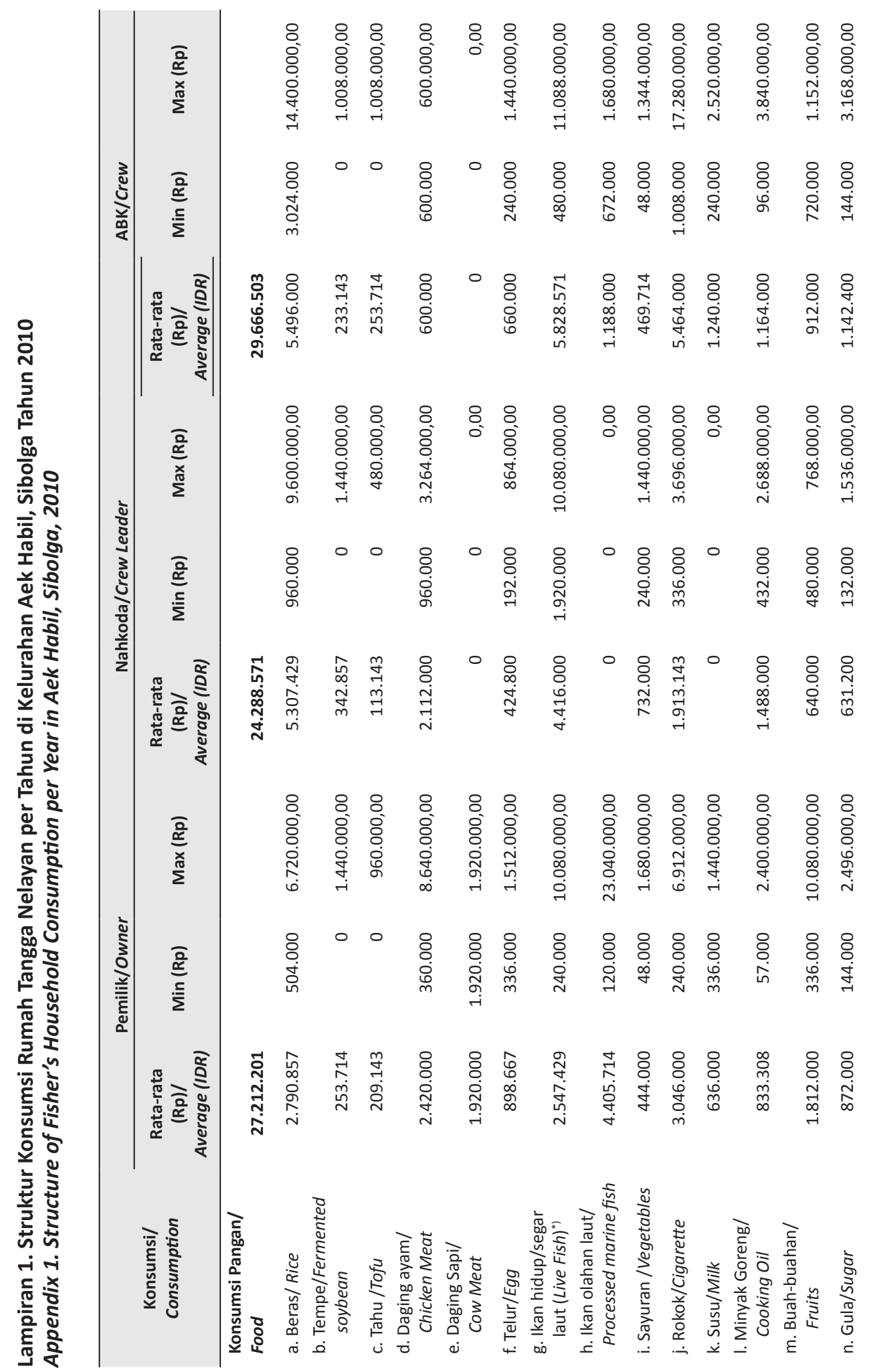




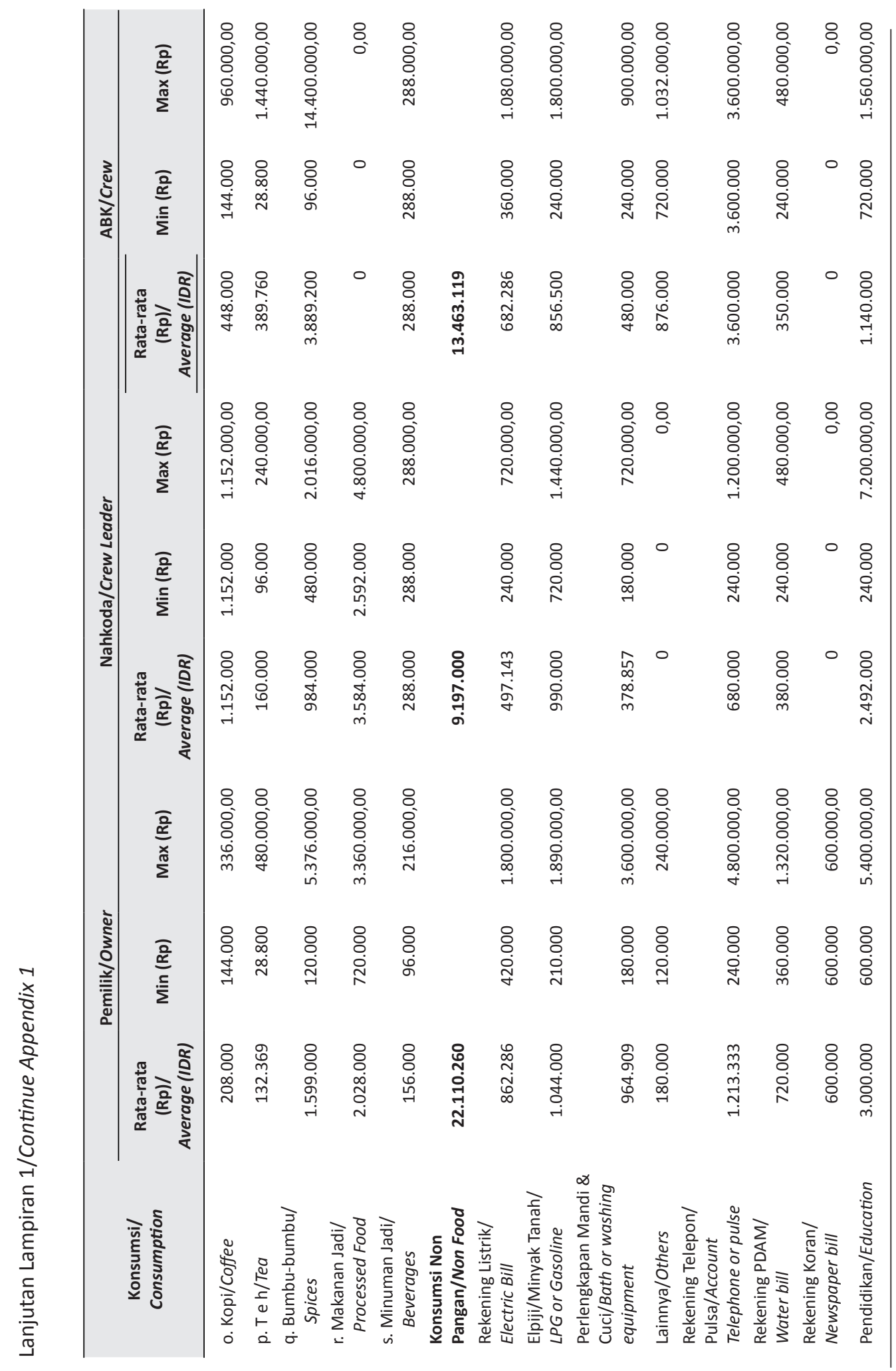




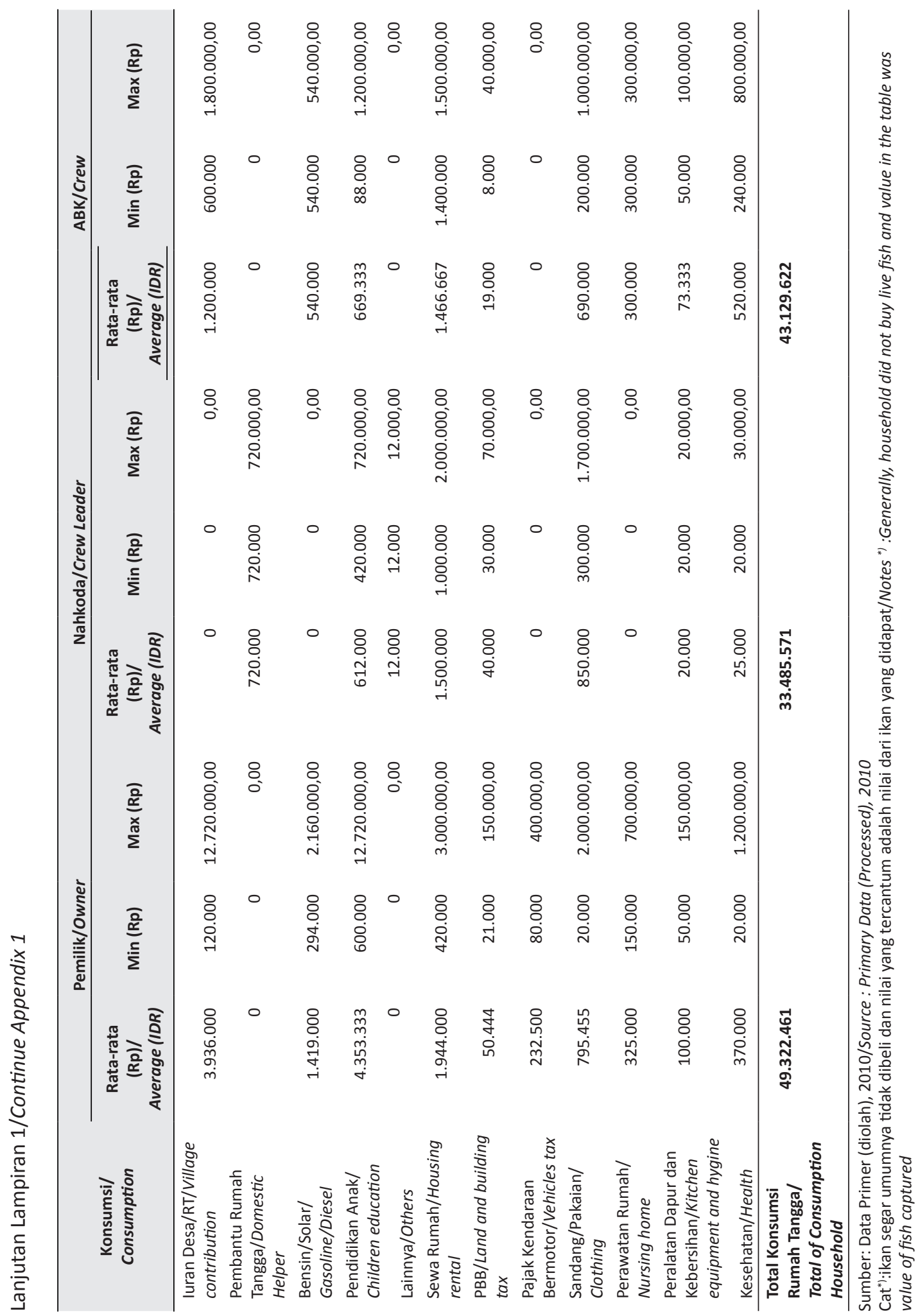

